\title{
Research on Control Strategy of Hydraulic Regenerative Braking of Electrohydraulic Hybrid Electric Vehicles
}

\author{
Qinghai Zhao $(\mathbb{D}$, Hongxin Zhang $\mathbb{D}$, and Yafei Xin \\ National and Local Union Engineering Research Center of Electric Vehicle Intelligent Power Integration Technology, \\ School of Electromechanic Engineering, Qingdao University, Qingdao 266071, China \\ Correspondence should be addressed to Hongxin Zhang; qduzhx@126.com
}

Received 9 August 2020; Revised 26 December 2020; Accepted 13 January 2021; Published 2 February 2021

Academic Editor: Salman saleem

Copyright ( 2021 Qinghai Zhao et al. This is an open access article distributed under the Creative Commons Attribution License, which permits unrestricted use, distribution, and reproduction in any medium, provided the original work is properly cited.

The vehicle will generate an amount of current while the electric vehicle just starting to regeneratively brake. In order to avoid the impact of high current on the traction battery, a novel electrohydraulic hybrid electric vehicle has been proposed. The main power source is supplied by the electric drive system, and the hydraulic system performs the auxiliary drive system that fully exerts the advantages of the electric drive system and the hydraulic drive system. A proper regenerative braking control strategy is presented, and the control parameters are determined by the fuzzy optimization algorithm. The simulation analysis built the model through the united simulation of AMESim and MATLAB/Simulink. The results illustrated that the optimized control strategy can reduce battery consumption by $1.22 \%$ under NEDC-operating conditions.

\section{Introduction}

Under the trend of environmental protection and energy crisis, the research and development of new-type energy vehicles strike at the automotive industry. Regenerative braking technology is a crucial element for new energy vehicles that are employed the principle of motor fourquadrant operation to recover braking energy. The recovered energy will be recycled and reused to increase the driving displacement of the vehicle. However, when the electric vehicle starts regenerative braking, the motor will generate a large inrush current that influences the battery life when the current directly charges the battery.

Liu et al. [1] established a mathematical model for the composite braking of hydraulic hybrid electric vehicles and proposed a regenerative braking control strategy. The results showed that it had a strong ability to recover braking energy. Paul et al. [2] proposed a braking force distribution strategy for full-time four-wheel-drive electric vehicles based on the estimation of tire-road friction coefficient $\mu$ and used fuzzy logic estimation methods. Wang et al. [3] discussed the braking sensation consistency strategy from two aspects: multiobjective optimization and compensation control.
Heydari et al. [4] introduced an efficient strategy for dynamically monitoring the minimum speed threshold. To alleviate the limited driving range of electric vehicles per charge, Liang et al. [5] studied a dual-clutch transmission based on regenerative braking. Poria et al. [6] presented a new method to simulate the braking performance of the electric vehicle on the motor dynamometer test bench. Ko et al. [7] developed a hybrid vehicle braking system based on automatic transmission and proposed a regenerative braking coordinated control algorithm. Yang et al. [8] proposed a new type of electrohydraulic hybrid power transmission system with hydraulic pressure and applied it to pure electric vehicle. Niu et al. [9] introduced an electrohydraulic hybrid power transmission system for urban vehicles and verified the advantages of the system through simulation and experiments. Honey et al. [10] established the model of an electrohydraulic hybrid electric vehicle and compared it with a baseline battery electric vehicle under urban driving cycle conditions. The results illustrated that energy consumption and current transients were reduced at the same time. Serrao et al. [11] introduced the form of the energy management problem of hybrid electric vehicles and compared three known methods to solve the final optimization problem. Lv 
et al. [12] proposed a hybrid braking control algorithm. The simulation results demonstrated that the proposed algorithm can significantly improve the vehicle's braking performance and hybrid braking control accuracy. Li et al. [13] proposed an adaptive online prediction method with a variable prediction range. Li et al. [14] applied a fuzzy control method to design a braking control strategy and verified the effectiveness of the strategy through simulation. Ko et al. [15] proposed an effective regenerative braking coordinated control algorithm to improve the energy recovery rate when the wheels are unlocked.

In this paper, the electrohydraulic hybrid transmission system will be studied, which is a new type of hybrid transmission. This paper will focus on regenerative braking, propose a control strategy, optimize the fuzzy rules.

A brief outline of this paper is as follows: in Section 2, the matching and selection of electrohydraulic hybrid electric vehicles are briefly introduced. The regenerative braking control strategy is designed in Section 3. In Section 4, the effectiveness of the control strategy is verified by simulation. In Section 5, a fuzzy optimization method is proposed to optimize the control strategy. Finally, some conclusions and remarks are provided in Section 6.

\section{Structure of the Electrohydraulic Hybrid Electric Vehicles}

Considering the problems of insufficient power density of the power transmission system of pure electric vehicles and low recovery rate of inertial energy at low and medium speeds, a novel electrohydraulic hybrid electric vehicle has been proposed to incorporate an additional hydraulic power system for assisting the vehicle driving process and recovering the braking energy. The system possesses two power conversion devices, including the electric motor and hydraulic pump motor, as well as two energy storage components, including the power batteries and hydraulic accumulator. The hydraulic system contains hydraulic accumulators, hydraulic pumps/motors, and pressure sensors. Under the normal operating conditions, the electrohydraulic hybrid vehicle is driven by the motor alone. However, the auxiliary hydraulic system participates in the demand of the high power when the vehicles process starting, climbing, or accelerating conditions. According to the energy state of the power batteries and the accumulator and the driver's braking intention during vehicle braking process, the control unit determines the specific adopted braking mode. There are three independent-type braking modes including, hydraulic regenerative braking mode, motor regenerative braking mode, and mechanical braking mode. In addition, to ensure emergency braking safety, only mechanical braking is performed. In the energy supply system of the electrohydraulic hybrid vehicle, the battery motor system mainly provides power and energy. The hydraulic power system composed of hydraulic accumulator and hydraulic motor assists in providing power and energy. According to the power demand, the motor is determined with the peak torque of $208 \mathrm{~N} \cdot \mathrm{m}$ and the peak speed of $9000 \mathrm{r} / \mathrm{min}$. For the hydraulic drive system, a hydraulic pump/motor is selected with the displacement of $100 \mathrm{cc} / \mathrm{rev}$ and the rotation speed of $1000 \mathrm{rev} / \mathrm{min}$.

The regenerative braking system is based on its unique electric power transmission system and hydraulic power transmission system, including the braking energy recovery of the battery motor and the braking energy recovery of the hydraulic pump hydraulic accumulator. Normally, the hydraulic system will be applied for braking energy recovery under the vehicle at low speed. The secondary component hydraulic pump/motor works in the pump state, and the kinetic energy on the axle drives the hydraulic pump to rotate, pumping the hydraulic oil in the low-pressure accumulator to the high-pressure accumulator. The energy device realizes the conversion of mechanical energy to hydraulic energy. At a higher speed level, the motor is adopted for braking energy recovery. If the battery capacity reaches full state as well as the vehicle at high-speed level, the hydraulic system is used for energy recovery. In the main energy supply system, the battery pack provides energy storage that has the characteristics of high energy density and fast response. As the main energy storage device, the battery pack is chosen with the voltage of $310 \mathrm{~V}$ and the rated capacity of $65 \mathrm{Ah}$. A parallel and then a series pattern are adopted in the battery pack, and the number of battery modules connected in series is 6 . In each battery module, the number of battery cells connected in series is 40 . The parameters of the battery pack are shown in Table 1.

In the auxiliary energy supply system, the hydraulic accumulator plays the role of providing energy storage. Hydraulic accumulator has the characteristics of high power density and high energy recovery rate, which is used as an auxiliary energy storage system. The maximum pressure of the high-pressure accumulator is $30 \mathrm{MPa}$, the gas precharge pressure is $10 \mathrm{MPa}$, and the volume is $35 \mathrm{~L}$. The maximum pressure of the low-pressure accumulator is $20 \mathrm{MPa}$, the gas precharge pressure is $10 \mathrm{MPa}$, and the volume is $35 \mathrm{~L}$. The parameters of the two kinds of accumulators are shown in Table 2.

\section{Regenerative Braking Control Strategy Design}

3.1. Control Strategy Logic. The motion mode of the automobile is divided into three basic modes: parking mode, driving mode, and braking mode. In the driving mode, it is divided into pure electric driving mode and electrohydraulic hybrid driving mode. In the braking mode, it is divided into mechanical braking mode and regenerative braking mode. The regenerative braking mode is divided into motor regenerative braking mode and hydraulic system regenerative braking mode.

In the basic three working modes, according to the speed signal, accelerator pedal signal, and brake pedal signal, the working mode conversion is carried out. The driving mode is converted according to the vehicle speed signal and highpressure accumulator signal. The braking mode is converted from mechanical braking mode to regenerative braking mode according to battery signal and high-pressure accumulator signal. If the battery signal is greater than 0.9 , when 
TABLE 1: Battery pack parameters.

\begin{tabular}{lcc}
\hline Battery pack parameters & Value & \\
\hline Voltage & 310 & Unit \\
Capacity & 65 & V \\
Number of battery modules connected in parallel & 1 & - \\
Number of battery modules connected in series & 6 & - \\
Number of battery cells connected in series for each battery module & 40 & - \\
\hline
\end{tabular}

TABle 2: Accumulator parameters.

\begin{tabular}{lccc}
\hline Accumulator parameters & High-pressure accumulator & Low-pressure accumulator & Unit \\
\hline Maximum pressure & 30 & 20 & $\mathrm{MPa}$ \\
Gas precharge pressure & 10 & 10 & $\mathrm{MPa}$ \\
Volume & 35 & 35 & $\mathrm{~L}$ \\
\hline
\end{tabular}

the high-pressure accumulator signal is greater than or equal to 0.9 or the low-pressure accumulator signal is less than or equal to 0.1 , the mechanical braking mode is entered. If the signal of a high-pressure accumulator is less than 0.9 and the signal of the low-pressure accumulator is greater than 0.1 and the signal of the battery is less than 0.9 , regenerative braking mode will be entered. If the SOC signal of the battery is less than 0.9 under the premise that the SOC signal of the high-pressure accumulator is less than 0.9 and the SOC signal of the low-pressure accumulator is greater than 0.1 , the regenerative braking mode is entered. Secondly, in regenerative braking mode, motor regenerative braking mode and hydraulic regenerative braking mode are converted according to vehicle speed signal and battery signal.

3.2. Control Strategy Mechanism. In stop mode, all output signals are 0.

The SOC of the accumulator can be described as follows:

$$
\mathrm{SOC}=\frac{P-P_{0}}{P_{2}-P_{0}}
$$

where $P$ is the current pressure, $P_{0}$ is the gas precharge pressure, and $P_{2}$ is the maximum pressure.

The displacement of the secondary element (hydraulic pump/motor) is $v=100 \mathrm{ml} / r$, and the torque calculation formula is represented as

$$
T=\frac{\beta \cdot V \cdot \Delta P}{20 \cdot \pi},
$$

where $\beta$ is the opening of the swash plate $(-1,1)$ and $\Delta P$ is the pressure difference between the high-pressure accumulator and the low-pressure accumulator.

In pure motor driving mode, the torque signal of motor is controlled. In formula (3), according to the accelerator pedal signal and the external characteristic curve of the motor, the required motor torque under the current operating speed is obtained as

$$
T \cdot \operatorname{Acc}=T_{m}
$$

where $T$ is the torque at the current voltage and speed obtained by looking up the table, $A_{c c}$ is the accelerator pedal signal $(0-100 \%)$, and $T_{\mathrm{m}}$ is the actual torque signal of the motor.

In the electrohydraulic hybrid mode, the motor and hydraulic motor jointly provide power for the vehicle. The motor system and hydraulic system distribute the torque according to $50 \%$ and $50 \%$ distribution ratio. Power distribution is controlled by controlling torque distribution. According to the acceleration pedal signal and the motor external characteristic curve, the motor torque is obtained. Furthermore, the required torque at the current speed is obtained. $50 \%$ of the torque is distributed to the motor.

The swash plate opening of the hydraulic motor is calculated as follows:

$$
\beta=\frac{T \cdot \operatorname{Acc} \cdot 0.5 \cdot 20 \cdot \pi}{100 \cdot \Delta P} .
$$

The torque provided by the hydraulic motor is compared with the required torque. When the hydraulic motor cannot meet the demand, the motor provides compensation torque, which is defined as

$$
T \cdot \text { Acc } \cdot 0.5+\left(T \cdot \text { Acc } \cdot 0.5-\frac{\Delta p \cdot 100 \cdot \beta}{20 \cdot \pi}\right)=T_{m} .
$$

Mechanical braking mode outputs vehicle brake signal. According to the current brake pedal signal and the maximum braking torque of the front axle, the braking torque required by the current working condition is obtained as

$$
\text { br } \cdot 1000=T_{b}
$$

where $b r$ is the brake pedal signal $(0-100 \%)$ and $T_{b}$ is the braking torque provided by vehicle brake.

In the regenerative braking mode, negative torque is output to recover braking energy. Through the current brake pedal signal and the maximum braking torque of the front axle, the braking torque required at the axle under the current working condition is obtained. The torque provided by the current motor can be obtained by the external characteristics of the motor. If the required braking torque is greater than the torque provided by the motor, the motor will work according to the current torque. The rest of the torque is compensated by the vehicle brake. If the required braking torque is less than or equal to the torque provided by 
the motor, the motor torque will work according to the current required braking torque.

The torque required by the vehicle brake is defined as

$$
|b r \cdot 1000-T \cdot 5|=T_{b} .
$$

The braking torque required by the motor can be divided into two situations. In one case, the braking torque required at the axle is greater than the motor torque transmitted from the axle:

$$
T=T_{m}
$$

In another case, the braking torque required at the axle is equal to or less than the motor torque transmitted from the axle that is defined as

$$
\frac{b r \cdot 1000}{5}=T_{m}
$$

Under the hydraulic regenerative braking mode, the braking torque required at the axle and the torque provided by the hydraulic pump/motor is calculated. If the required braking torque is greater than that provided by the hydraulic pump, the swash plate angle is calculated according to the current torque provided by the hydraulic pump. The rest of the torque is compensated by the vehicle brake. If the required braking torque is less than that provided by the hydraulic pump, the angle of the swash plate of the hydraulic pump is calculated according to the required braking torque. Therefore, the calculation of torque signal required by vehicle brake is defined as

$$
b r \cdot 1000-\frac{1 \cdot 100 \cdot \Delta p}{20 \cdot \pi}=T_{b} .
$$

The opening signal of swash plate can be divided into two cases. When the torque required at the axle is greater than the torque transmitted to the axle by the hydraulic pump, the swash plate is opened according to the maximum opening. At this time, the hydraulic pump provides the maximum torque that can be provided. The rest of the torque is compensated by the vehicle brake. When the torque required at the axle is equal to or less than the torque transmitted to the axle provided by the hydraulic pump, the calculation method of swash plate opening is defined as

$$
k=\frac{(b r \cdot 1000 / 5) \cdot 20 \cdot \pi}{\Delta p \cdot 100},
$$

where $k$ is the swash plate opening signal.

In the conversion, it should be noted that the required braking torque calculated is at the axle. When calculating the swash plate angle, it is necessary to convert the speed ratio. The speed ratio of the selected coupler is 5. The maximum energy that the accumulator can recover during braking is shown in the following formula:

$$
E_{\text {hreg }}=\frac{p_{0} V_{0}}{n-1}\left[\left(\frac{p_{0}}{p_{2}}\right)^{(1-n / n)}-1\right],
$$

where $E_{\text {hreg }}$ is the maximum energy that can be recovered by the accumulator, $p_{0}$ is the precharge pressure of the accumulator, $p_{2}$ is the maximum working pressure of the accumulator, $V_{0}$ is the gas volume corresponding to the pressure $p_{0}$, and $n$ is the variable index of the gas.

The minimum working pressure of the accumulator is shown as

$$
p_{1}=(0.6 \sim 0.85) p_{2} .
$$

The recovery rate of braking energy of the hydraulic system is formulated as

$$
\eta=\frac{E_{h r e g}}{E},
$$

where $\eta$ is the braking energy recovery rate, $E$ is the kinetic energy of the vehicle. $E$ is the kinetic energy under a certain vehicle working condition, defined as

$$
E=\frac{1}{2} m\left(v_{2}-v_{1}\right)^{2}
$$

where $m$ is the mass of the vehicle, $v_{1}$ is the initial speed, and $v_{2}$ is the final speed.

\section{Control Strategy Simulation}

4.1. Vehicle Modeling. In this paper, AMESim is used for modeling and simulation. The peak torque of the motor is $208 \mathrm{Nm}$, and the peak speed is $9000 \mathrm{r} / \mathrm{min}$. The parameters of the battery pack in the model are defined as follows: the initial SOC is $90 \%$, the voltage is $310 \mathrm{~V}$, and the rated capacity is $65 \mathrm{Ah}$. The electrohydraulic hybrid electric vehicle model is shown in Figure 1.

4.2. Control Strategy Modeling. In this paper, the regenerative braking control strategy based on the maximum energy recovery principle is adopted. The control strategy model includes mode switching and energy management. The mode switching part includes parking mode, driving mode, and braking mode. The driving mode is divided into pure motor driving mode and electrohydraulic hybrid driving mode. The braking mode is divided into motor regenerative braking mode and hydraulic regenerative braking mode.

The state-flow state machine in MATLAB/Simulink is used to realize the mode switching function. Firstly, according to the vehicle speed signal, accelerator pedal signal, and brake pedal signal, the control strategy determines which mode works. If the brake pedal signal is 0 and the accelerator pedal signal is greater than 0 , the control strategy works in drive mode. If the vehicle speed signal is greater than 0 and the brake pedal signal is greater than 0 , the control strategy works in braking mode.

In the following three situations, the control strategy works in the parking mode:

(1) Vehicle speed signal is 0

(2) The vehicle speed signal is 0 , and the brake pedal signal is greater than 0

(3) The vehicle speed signal is less than or equal to 0 , and the brake pedal signal is greater than 0 


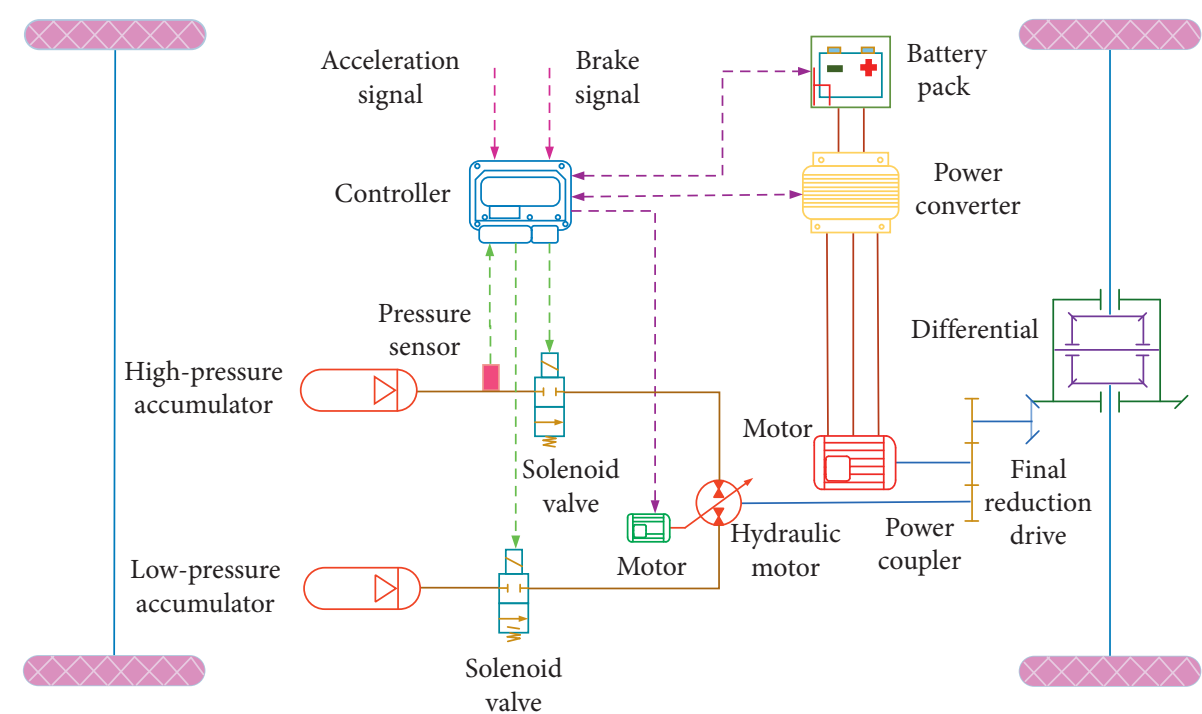

FIGURE 1: Electrohydraulic hybrid electric vehicle model.

In the drive mode, pure motor drive mode $(\mathrm{EV})$ is entered by default. If the vehicle speed is greater than or equal to 10, the SOC of the high-pressure accumulator is greater than 0.1, and the pressure of the high-pressure accumulator is $10 \%$ higher than that of the low-pressure accumulator, the control strategy works in the EHV mode.

In the braking mode, the control strategy firstly works in the regenerative braking mode (RGB). If the SOC of the battery is greater than 0.9 , the pressure of the high-pressure accumulator is greater than or equal to 0.9 , and the pressure of the low-pressure accumulator is less than or equal to 0.1, the control strategy works in the mechanical braking mode.

In the regenerative braking mode, the control strategy firstly works in the hydraulic regenerative braking mode. If the vehicle speed is higher than the minimum speed of motor regenerative braking, the high-pressure accumulator charging or low-voltage accumulator discharging is completed, and the battery SOC is less than 0.9 , the control strategy works in the motor regenerative braking mode (ERGB).

The energy management part corresponds to each driving mode and braking mode in the mode switching, which controls the motor torque, vehicle brake torque, and swash plate opening.

4.3. Simulation Results and Analysis. The vehicle model and control strategy model are jointly simulated under NEDC conditions. After the simulation, the simulation speed is compared with the speed required by the working conditions, as shown in Figure 2. The results show that further parameter analysis can be carried out.

The torque curve of the motor is shown in Figure 3. It can be seen that the change of motor output torque can be up to $90 \mathrm{Nm}$. The four cycles in the first half of the torque curve correspond to the four urban driving conditions in the NEDC cycle. The second half correspond to the driving cycle of suburban road conditions. In the simulation stage, the

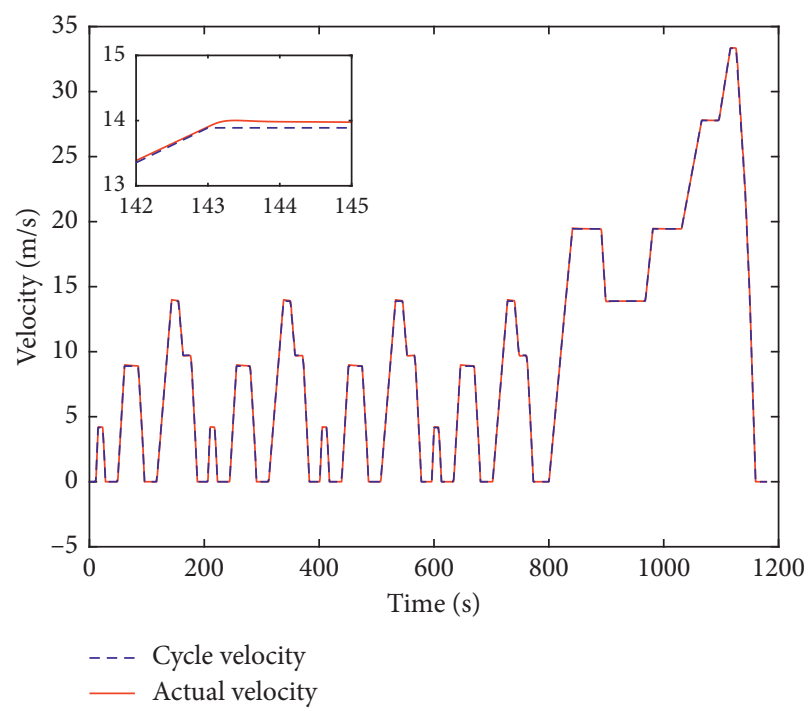

Figure 2: Speed following curve.

torque output of the motor is controlled according to the speed requirement of the working condition.

The SOC curve of the battery is shown in Figure 4. The initial SOC of the battery is $90 \%$. The curve showed a decreasing trend. It means that electric energy is consumed all the time during the operation. There are fluctuations during the descent. This represents the recovery of brake energy.

In the braking process, the kinetic energy at the axle is transmitted to the motor through the power transmission system. In the braking process, the kinetic energy at the axle is transmitted to the motor through the power transmission system. At this time, the motor works as a generator. The energy is converted into electrical energy and stored in the battery of the energy storage device. This process completes the recovery of braking energy. These energies can be reused to achieve energy-saving effect. In the process of braking, the motor works in the state of the generator and also provides 


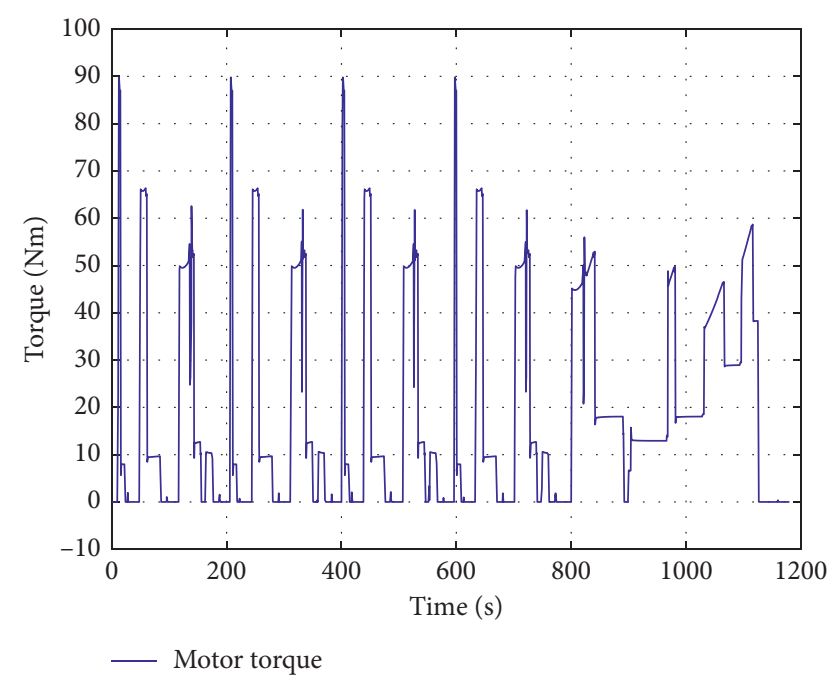

Figure 3: Motor torque curve.

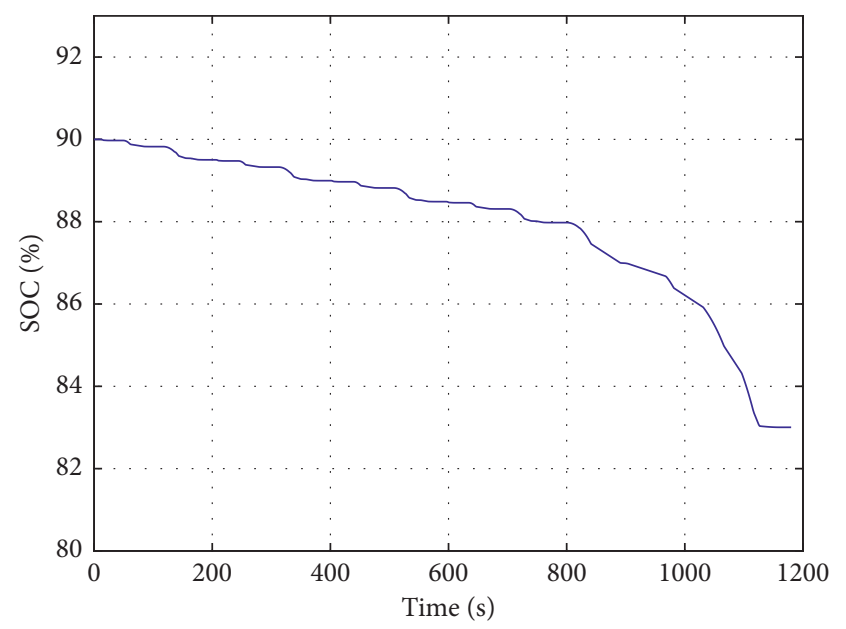

— Battery SOC

FIgURE 4: The battery SOC curve.

braking torque for the axle. The braking torque is transmitted to the axle through the power transmission system to realize braking or parking.

The swash plate opening curve is shown in Figure 5. The opening of swash plate refers to the inclined angle of swash plate of hydraulic pump motor, and its range is between -1 and 1 . When the swash plate angle range is $(-1,0)$, it means that the secondary element is working in the state of the hydraulic pump. When the angle range of swash plate is $(0,1)$, it means that the secondary element works in the state of the hydraulic motor.

The charging and discharging curves of the high-pressure accumulator and low-pressure accumulator are shown in Figure 6. In the figure, the red line represents the pressure of the high-pressure accumulator with an initial pressure of 300 bar. The blue line represents the pressure of the lowpressure accumulator with an initial pressure of 200 bar. At the end of the cycle, the final pressure value of the

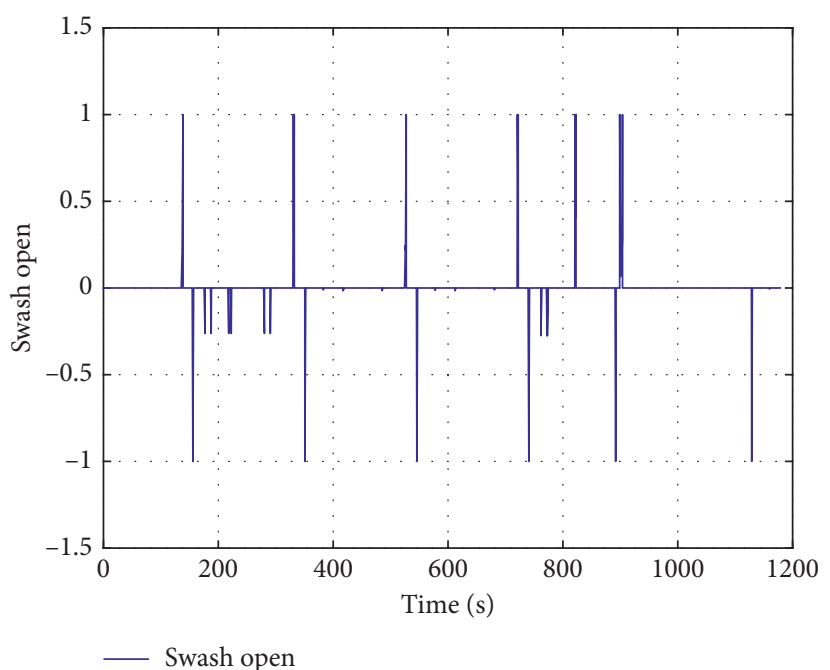

Figure 5: The swash plate opening curve.

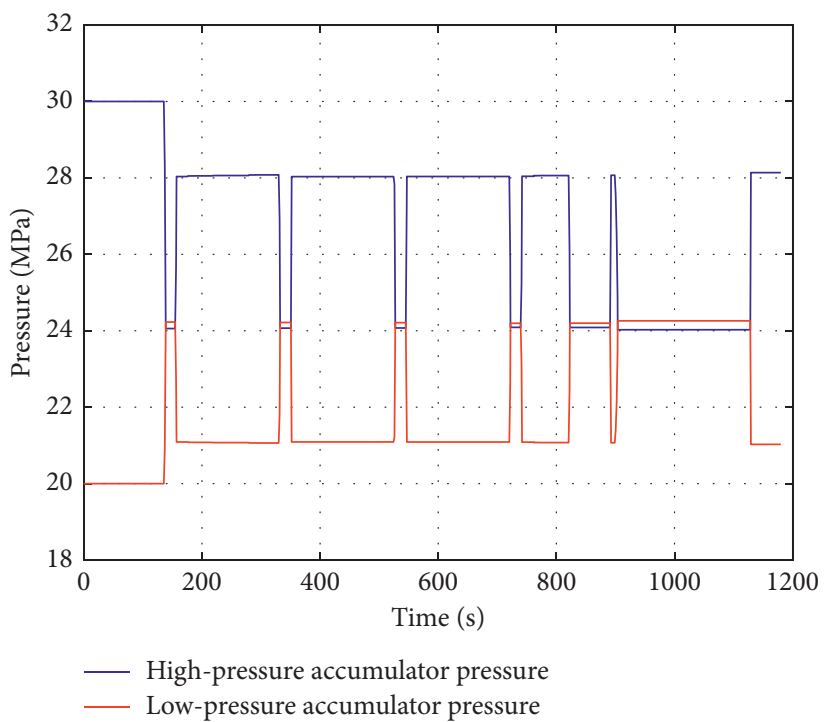

FIgURE 6: The charging and discharging curves.

high-pressure accumulator is $28.1 \mathrm{MPa}$. The pressure value of low-pressure accumulator is $21 \mathrm{MPa}$.

The capacity change curve of the accumulator is shown in Figure 7. The change of capacity and pressure presents the opposite trend. When the accumulator pressure is high, its capacity is relatively small. When the pressure of the accumulator is low, its capacity is relatively large.

According to empirical equation (13), the minimum working pressure of the high-pressure accumulator is $18 \mathrm{MPa}-25.5 \mathrm{MPa}$. The minimum working pressure is $18 \mathrm{MPa}$. Taking the deceleration braking condition of 1125 s-1160 s on NEDC suburban road as an example, the braking energy recovery rate of this section is calculated. Under this condition, the kinetic energy of the vehicle is $0.19 \mathrm{kWh}$ according to equation (15). According to equation (12), the energy recovered by the hydraulic system is $0.05 \mathrm{kWh}$. Thus, the energy recovery rate of the electrohydraulic hybrid system is $26.32 \%$. 


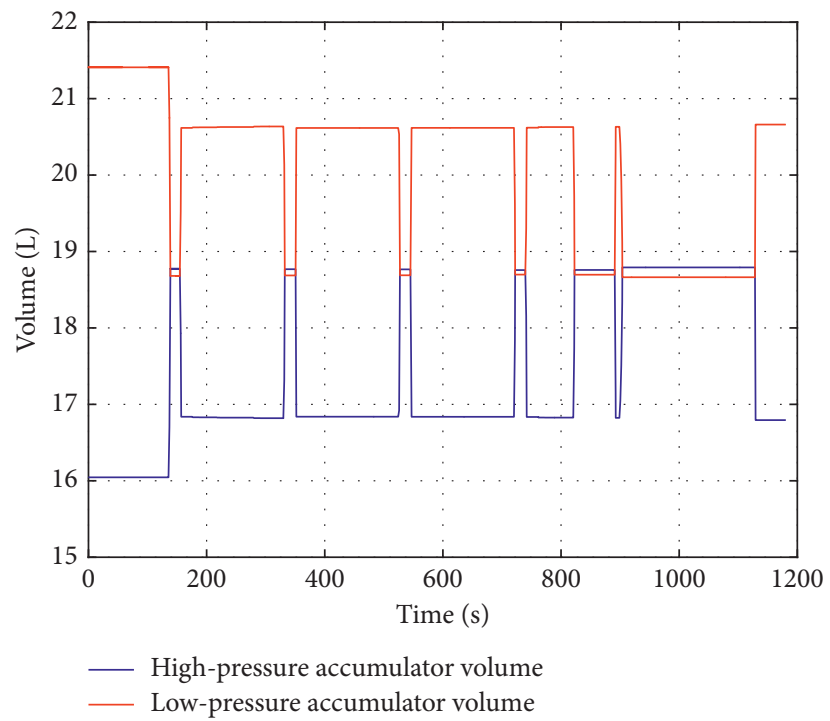

Figure 7: The capacity change curve.

\section{Control Strategy Optimizations}

The fuzzy control rules are designed by using the fuzzy toolbox of MATLAB software and then conduct joint simulation with the vehicle model. The fuzzy controller is established.

5.1. Fuzzy Controller Design. The fuzzy controller with double input and double output is designed in Matlab/ Simulink software. The fuzzy controller consists of two inputs and two outputs. The two inputs are the battery SOC signal and braking strength signal. The fuzzy controller consists of two inputs and two outputs, as is shown in Figure 8.

The establishment of fuzzy control rules determines how to control the input and output signals. The input signal and output signal are represented by $L, M$, and $H$, respectively. They are different combinations to create a fuzzy control rule table, as shown in Table 3.

5.2. Fuzzy Optimization Control Strategy Modeling. On the basis of the control strategy model, the fuzzy controller is added to constitute the fuzzy control optimization model, as shown in Figure 9.

By introducing the braking coefficient of front axle and rear axle, the braking pressure is converted into braking strength. The calculation module of the front axle braking coefficient and rear axle braking coefficient is shown in Figure 10. The brake strength module is shown in Figure 11.

5.3. Simulation Analysis of Fuzzy Optimal Control Strategy. On the joint simulation platform composed of AMESim software and MATLAB/Simulink software, the fuzzy control optimization model is simulated and analyzed. Under NEDC conditions, the effect of the optimized control strategy on reducing battery SOC consumption was tested, as shown in Table 4. During the 1180 s of NEDC, the SOC of the battery increased from $83.00 \%$
TABle 3: Fuzzy rule table.

\begin{tabular}{|c|c|}
\hline Analyzing conditions & Result \\
\hline (1) If (SOC is $L$ ) and ( $z$ is $L$ ) & Then (REG is $L$ ) \\
\hline (2) If (SOC is $L)$ and ( $z$ is $M$ ) & Then (REG is $L$ ) \\
\hline (3) If (SOC is $L)$ and ( $z$ is $H$ ) & Then (REG is $L$ ) \\
\hline (4) If (SOC is $L$ ) and ( $z$ is $L$ ) & Then (REG is $M$ ) \\
\hline (5) If (SOC is $L)$ and ( $z$ is $M$ ) & Then (REG is $M$ ) \\
\hline (6) If (SOC is $L$ ) and ( $z$ is $H$ ) & Then (REG is $M$ ) \\
\hline (7) If (SOC is $L$ ) and ( $z$ is $L$ ) & Then (REG is $H$ ) \\
\hline ...... & \\
\hline (48) If (SOC is $H$ ) and ( $z$ is $H$ ) & Then (FRIC is $L$ ) \\
\hline (49) If (SOC is $H$ ) and ( $z$ is $L$ ) & Then (FRIC is $M$ ) \\
\hline (50) If (SOC is $H$ ) and ( $z$ is $M$ ) & Then (FRIC is $M$ ) \\
\hline (51) If (SOC is $H)$ and ( $z$ is $H$ ) & Then (FRIC is $M$ ) \\
\hline (52) If (SOC is $H$ ) and ( $z$ is $L$ ) & Then (FRIC is $H$ ) \\
\hline (53) If (SOC is $H$ ) and ( $z$ is $M$ ) & Then (FRIC is $H$ ) \\
\hline (54) If (SOC is $H$ ) and ( $z$ is $H$ ) & Then (FRIC is $H$ ) \\
\hline
\end{tabular}

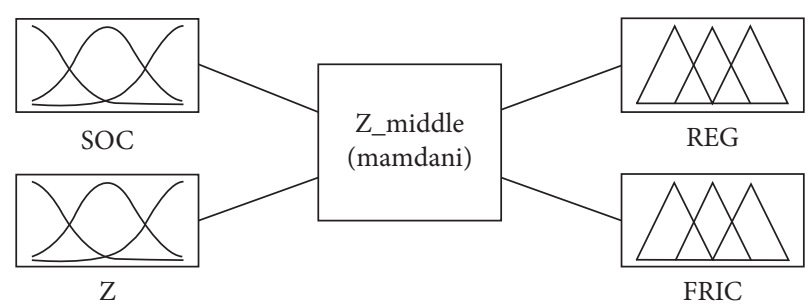

FIgURE 8: Fuzzy controller structure.

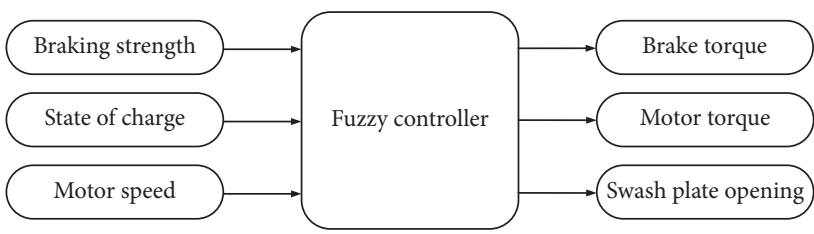

FIGURE 9: ERGB mode after adding the fuzzy controller. 


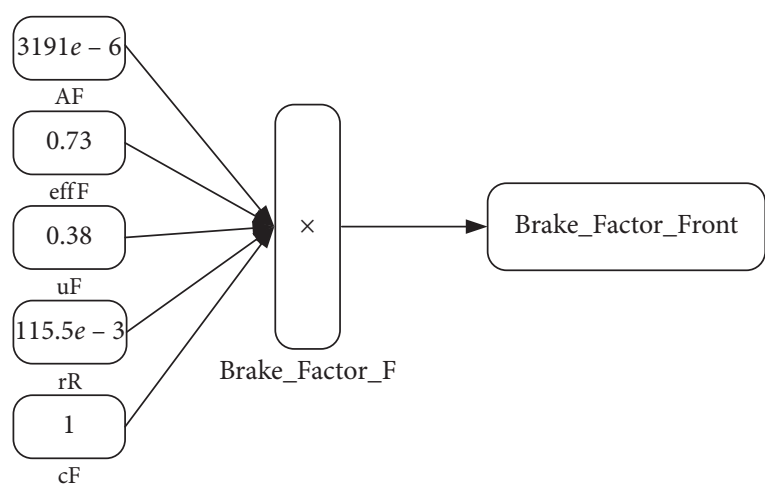

(a)

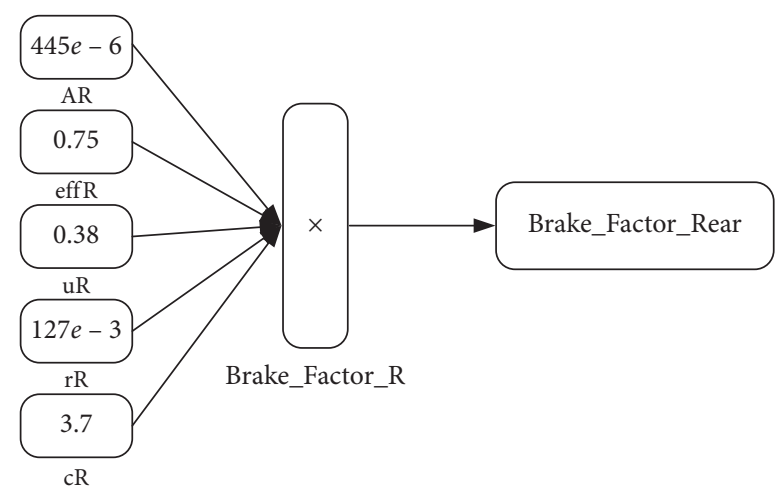

(b)

Figure 10: Calculation module of front and rear axle braking coefficient.

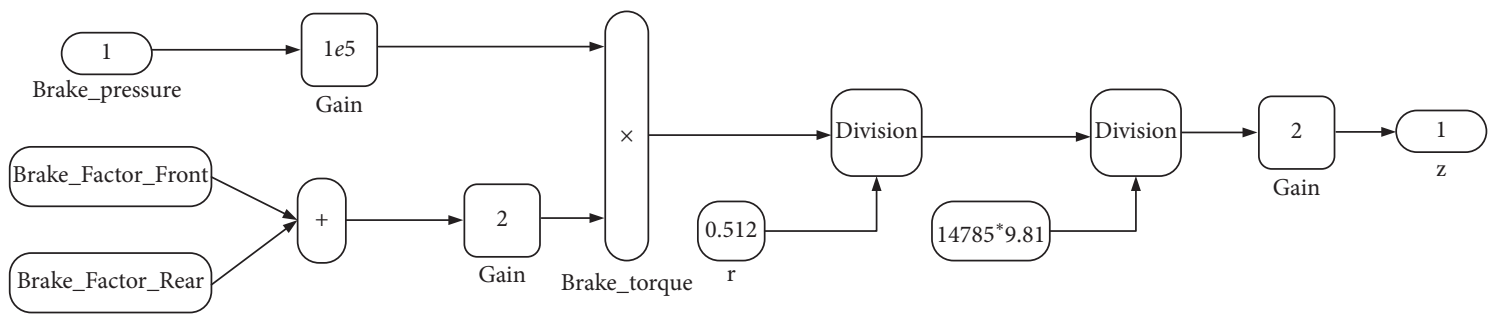

FIGURE 11: Conversion module of brake pressure to brake strength.

TABLE 4: SOC consumption reduction value under cycling conditions.

\begin{tabular}{lccc}
\hline. & Final value of strategy SOC before optimization (\%) & Final value of SOC after optimization (\%) & Reduce consumption (\%) \\
\hline NEDC cycle & 83.00 & 84.22 & 1.22
\end{tabular}

under the optimized control strategy to $84.22 \%$ under the optimized control strategy. The SOC consumption is reduced by $1.22 \%$.

\section{Conclusions}

(1) An electrohydraulic hybrid transmission system is studied. According to the operation mechanism of the electric hydraulic hybrid electric vehicle, the power transmission system structure of the electric hydraulic hybrid electric vehicle is deeply explored. The vehicle model was built. A new configuration is proposed for the development of hybrid electric vehicles.

(2) A regenerative braking control strategy based on the principle of the maximum energy recovery rate was studied. On the basis of conforming to the braking regulations, the braking force distribution method is analyzed. The regenerative braking control strategy for the electric hydraulic hybrid electric vehicle was proposed.

(3) The fuzzy control method was used to optimize the control strategy. Through the joint simulation, the rationality and effectiveness of the optimized control strategy were verified. After optimization, the battery consumption was reduced by $1.22 \%$ under NEDC conditions.
(4) The method of this paper has not been verified by the real vehicle. The control strategy will be verified by hardware-in-the-loop simulation in the future.

\section{Data Availability}

The data used to support the findings of this study are available from the corresponding author upon request.

\section{Conflicts of Interest}

The authors declare that they have no conflicts of interest.

\section{Acknowledgments}

This research was supported by the Natural Science Foundation of China (no. 51705268), Shandong Provincial Natural Science Foundation, China (no. ZR2016EEB20), and China Postdoctoral Science Foundation Funded Project (no. 2017M612191).

\section{References}

[1] T. Liu, J. Zheng, Y. Su, and J. Zhao, "A study on control strategy of regenerative braking in the hydraulic hybrid vehicle based on ECE regulations," Mathematical Problems in Engineering, vol. 2013, Article ID 208753, 9 pages, 2013. 
[2] D. Paul, E. Velenis, D. Cao, and T. Dobo, "Optimal \$ $\backslash \mathrm{mu} \$$ -estimation-based regenerative braking strategy for an AWD HEV," IEEE Transactions on Transportation Electrification, vol. 3, no. 1, pp. 249-258, 2017.

[3] C. Wang, W. Zhao, and W. Li, "Braking sense consistency strategy of electro-hydraulic composite braking system," Mechanical Systems and Signal Processing, vol. 109, pp. 196219, 2018.

[4] S. Heydari, P. Fajri, Md. Rasheduzzaman, and R. Sabzehgar, "Maximizing regenerative braking energy recovery of electric vehicles through dynamic low-speed cutoff point detection," IEEE Transactions on Transportation Electrification, vol. 5, no. $1,2019$.

[5] J. Liang, P. D. Walker, J. Ruan, H. Yang, J. Wu, and N. Zhang, "Gearshift and brake distribution control for regenerative braking in electric vehicles with dual clutch transmission," Mechanism and Machine Theory, vol. 133, pp. 1-22, 2019.

[6] F. Poria, S. Lee, and F. Mehdi, "Modeling and integration of electric vehicle regenerative and friction braking for motor/ dynamometer test bench emulation," IEEE Transactions on Vehicular Technology, vol. 65, no. 6, pp. 4264-4273, 2016.

[7] J. Ko, S. Ko, H. Son, B. Yoo, J. Cheon, and H. Kim, "Development of brake system and regenerative braking cooperative control algorithm for automatic-transmission-based hybrid electric vehicles," IEEE Transactions on Vehicular Technology, vol. 64, no. 2, pp. 431-440, 2015.

[8] Y. Yang, C. Luo, and P. Li, "Regenerative braking control strategy of electric-hydraulic hybrid (EHH) vehicle," Energies, vol. 10, no. 7, p. 1038, 2017.

[9] N. Geng, F. Shang, M. Krishnamurthy, and M. Jose, "Design and analysis of an electric hydraulic hybrid powertrain in electric vehicles," IEEE Transactions on Transportation Electrification, vol. 3, no. 1, pp. 48-57, 2017.

[10] H. Emilio and S. In-Soo, "A feasibility study of an electrichydraulic hybrid powertrain for passenger vehicle," Proceedings of the Institution of Mechanical Engineers Part D-Journal of Automobile Engineering, vol. 229, no. 14, pp. 1894-1906, 2015.

[11] L. Serrao, S. Onori, and G. Rizzoni, "A comparative analysis of energy management strategies for hybrid electric vehicles," Journal of Dynamics Systems Measurement and ControlTransactions of the ASME, vol. 133, 2011.

[12] C. Lv, J. Zhang, and Y. Li, "Extended-Kalman-filter-based regenerative and friction blended braking control for electric vehicle equipped with axle motor considering damping and elastic properties of electric powertrain," Vehicle System Dynamics, vol. 52, no. 11, pp. 1372-1388, 2014.

[13] Y. Li, H. He, and J. Peng, "An adaptive online prediction method with variable prediction horizon for future driving cycle of the vehicle," IEEE Access, vol. 6, pp. 33062-33075, 2018.

[14] S. Li, Bo Yu, and X. Feng, "Research on braking energy recovery strategy of electric vehicle based on ECE regulation and I curve," Sciencce Progress, vol. 103, no. 1, Article ID $0036850419877762,2019$.

[15] J. W. Ko, S. Y. Ko, I. S. Kim, D. Y. Hyun, and H. S. Kim, “Cooperative control for regenerative braking and friction braking to increase energy recovery without wheel lock," International Journal of Automotive Technology, vol. 15, no. 2, pp. 253-262, 2014. 